\title{
3 Research Square

\section{Safety Profile of an Intracranial Multimodal Monitoring Bolt System for Neurocritical Care: A Single-Center Experience}

Mejdeddine Al Barajraji ( $\square$ mejdi.albarajraji@gmail.com )

Free University of Brussels: Universite Libre de Bruxelles https://orcid.org/0000-0002-9619-7324

Elisa GOUVEA BOGOSSIAN

Hopital Erasme Université Libre de Bruxelles (ULB)

Olivier DEWITTE

Hopital Erasme Université Libre de Bruxelles (ULB)

Nicolas GASPARD

Hopital Erasme Université Libre de Bruxelles (ULB)

Salim El Hadwe

Hopital Erasme Université Libre de Bruxelles (ULB)

Andrea MININI

Hopital Erasme Université Libre de Bruxelles (ULB)

Joachim ANDRE

Hopital Erasme Université Libre de Bruxelles (ULB)

Fabio Silvio TACCONE

Hopital Erasme Université Libre de Bruxelles (ULB)

Sophie SCHUIND

Hopital Erasme Université Libre de Bruxelles (ULB)

Sami BARRIT

Hopital Erasme Université Libre de Bruxelles (ULB)

\section{Research Article}

Keywords: PbtO2, acute brain injury, monitoring, complications

Posted Date: June 30th, 2021

DOI: https://doi.org/10.21203/rs.3.rs-621602/v1

License: (c) (1) This work is licensed under a Creative Commons Attribution 4.0 International License.

Read Full License 
Version of Record: A version of this preprint was published at Acta Neurochirurgica on September 8th, 2021. See the published version at https://doi.org/10.1007/s00701-021-04992-z. 


\section{Abstract \\ Background}

Intracranial multimodality monitoring (iMMM) is increasingly used in acute brain injured patients; however, safety and reliability remain major concerns to its routine implementation.

\section{Methods}

We performed a retrospective study including all patients undergoing $\mathrm{iMMM}$ at a single European center between July 2016 and January 2020. Brain tissue oxygenation probe $\left(\mathrm{PbtO}_{2}\right)$, alone or in combination with a microdialysis catheter and/or an 8-contact depth EEG electrode, was inserted using a triple lumen bolt system and targeting normal-appearing at risk brain area on the injured side, whenever possible. Surgical complications, adverse events and technical malfunctions, directly associated with iMMM were collected. A blinded imaging review was performed by an independent radiologist.

\section{Results}

113 patients with 123 iMMM insertions were included for a median monitoring time of 9 [3-14] days. Of those, $93(76 \%)$ patients had only $\mathrm{PbtO}_{2}$ probe insertion and $30(24 \%)$ had also microdialysis and/or iEEG monitoring. SAH was the most frequent indication for iMMM $(n=60,53 \%)$. At least one complication was observed in 67/123 (54\%) iMMM placement, corresponding to 58/113 (51\%) patients. Misplacement was observed in $16 / 123(13 \%)$, resulting in a total of $6 / 16(38 \%)$ malfunctioning $\mathrm{PbtO}_{2}$ catheters. Intracranial hemorrhage was observed in 14 iMMM placements (11\%), of which one required surgical drainage. Five placements were complicated by pneumocephalus and 4 with bone fragments, none of these requiring additional surgery. No CNS infection related to iMMM was observed. Seven (6\%) probes were accidentally dislodged and 2 probes (2\%) were accidentally broken. Ten $\mathrm{PbtO}_{2}$ probes (8\%) presented a technical malfunction after a median of 9 [ranges: 2-24] days after initiation of monitoring and 4 of them were replaced.

\section{Conclusions}

In this study, a high occurrence of complications related to iMMM was observed, although most of them did not require specific interventions and did not result in malfunctioning monitoring.

\section{Introduction}

Acute brain injury $(\mathrm{ABI})$, such as traumatic brain injury $(\mathrm{TBI})$ and subarachnoid hemorrhage $(\mathrm{SAH})$ are important causes of mortality, morbidity and economic burden worldwide [5, 7]. Monitoring of 
neurological function in $\mathrm{ABI}$ patients is mandatory to detect early neuro-worsening before irreversible damage occurs, to individualize and guide patients' care and to assess the effects of specific therapies [14].

Clinical examination is not always reliable in this setting, as some patients might be heavily sedated [2]. As such, specific neuro-monitoring tools can help to manage secondary brain injuries in these patients. In particular, invasive intracranial pressure (ICP) and derived cerebral perfusion pressure (CPP) are the cornerstone of neuro-monitoring in severe $\mathrm{ABI}$ patients, as reported by current guidelines [11], although mainly based on observational studies conducted in TBI patients [1, 3, 9]. Indeed a randomized control trial has failed to show any benefit of invasive ICP monitoring compared to clinical and imaging monitoring [4]. Moreover, in the era of precision medicine, a simplistic "one size fits all" strategy based only on fixed ICP/CPP target is not sufficient to optimize brain function; a complex tailored strategy for brain-injured patients based on multimodality monitoring and personalized integration of an array of data may be more adequate [15].

Intracranial multimodality monitoring (iMMM) has been implemented in many institutions, combining ICP monitoring with brain tissue oxygenation $\left(\mathrm{PbtO}_{2}\right)$ probes, microdialysis catheters $(\mathrm{MD}$, to assess cerebral metabolism) and intracortical or surface electroencephalography (iEEG, to detect seizures or cortical spread depolarizations) $[6,15]$. However, considering the unknown clinical significance of iMMM, concerns have been raised about its invasiveness, safety and technical reliability $[2,10]$.

As such, we aimed to evaluate a single-center experience about surgical placement and related complications, management, technical malfunctions, and adverse events of an iMMM implementation in $A B I$ patients.

\section{Methods}

\section{Study population}

All patients who underwent ICP monitoring combined with iMMM (i.e. $\mathrm{PbtO}_{2} \pm \mathrm{MD}$ and $\mathrm{iEEG}$ ) placement at a single European academic center between July 2016 and January 2020 were eligible for the study. The study protocol was approved by the institutional review board (P2020/019), which waived the need for a written consent. Medical charts and brain imaging were retrospectively reviewed for data collection.

\section{Invasive multimodality monitoring}

A triple lumen bolt allowing the insertion of a $\mathrm{PbtO}_{2}$ probe (IM3.ST_EU, Integra LifeSciences Corporation, Plainsboro, NJ, USA), alone (from July 2016 to December 2018) or in association (from January 2019 to January 2020) with an 8-contacts depth EEG electrode (Dixi Medical, Besançon, France) and a microdialysis catheter (M-Dialysis, Solna, Sweden), was placed in the operating room by a neurosurgeon in patients with $\mathrm{ABI}$ (i.e. TBI, SAH or intracranial hemorrhage, ICH), who had indications for ICP 
monitoring (i.e. abnormal CT-scan findings and a Glasgow Coma Score on admission < 9). The triple lumen bolt placement is shown in Figure 1.

A single $1 \mathrm{~g}$ dose of cefazolin was administered before incision with no continuation of prophylactic antibiotic afterwards. The bolt was positioned $1.5 \mathrm{~cm}$ anteriorly from the Kocher's point, targeting normalappearing brain area of the injured side or, in case of surgical constraints (i.e. need for craniectomy, large intracranial hematoma, large hydrocephalus) in the contralateral side. In case of aneurysmal SAH, the bolt was positioned on either the ipsilateral side of the aneurysm (i.e. anterior circulation) or on the right side (i.e. no aneurysm identified or aneurysm located in the posterior circulation). For patients with delayed clinical deterioration without previous $\mathrm{IMMM}$, the bolt was placed ipsilateral to the cerebral vasospasm and/or "at risk" area, as suggested by cerebral CT-scan perfusion. Drilling was performed using a manual craniotome assembled to a $5.3 \mathrm{~mm}$ twist drill-bit specifically designed. External ventricular drain (EVD) or intraparenchymal ICP monitoring were inserted through an adjoining distinct burr hole located at Kocher point.

\section{Data collection and definitions}

Demographics, indications for iMMM, severity scores on admission (Glasgow Coma Scale [19], Acute Physiologic Assessment and Chronic Health Evaluation -APACHE- II score[13], and Sequential Organ Failure Assessment -SOFA- score[20]) and hospital mortality were collected. Unfavorable neurological outcome was defined as a Glasgow Outcome Scale of 1-3 at hospital discharge. Working hours were defined from 8 am to $6 \mathrm{pm}$, Monday to Friday (excluding public holidays).

To describe iMMM-related events, surgical complications, adverse events and technical malfunctions were retrieved from medical records. Surgical complications were defined as: a) misplacement; $b$ ) intracranial hemorrhages (ICH); c) bone fragments; d) pneumocephalus and e) central nervous system (CNS) infections. Probe location in the subcortical anterior frontal area was considered as "optimal". Misplacement was therefore identified as non-optimally located probes, i.e. extra-axial, cortical matter, deep grey matter, paraventricular or intraventricular locations; $\mathrm{ICH}$, bone fragments and pneumocephalus were identified on cerebral CT-scans performed after iMMM implementation, which were reviewed by a radiologist blinded to the outcome of the patient. Also, ICH were classified as Grade I (i.e. $1 \mathrm{~mL}$ hemorrhage at any location along the iMMM), Grade II (i.e. $1 \mathrm{~mL}$ hemorrhage at any location along the iMMM) or Grade III (i.e. $>1 \mathrm{~mL}$ hemorrhage at any location along the iMMM or in the ventricle but contiguous to the catheter tip [16]), adapting a proposed classification for EVD-related hemorrhages. CNS infections were defined as meningitis, encephalitis and/or ventriculitis with microbiological documentation on CSF samples and local skin infection and/or material culture of iMMM, as defined by the $\mathrm{CDC} / \mathrm{NHSN}$ criteria [12] of hospital acquired infections. Adverse events included accidental dislodgement or breaking of any probe or bolt device, requiring replacement or withdrawal. "Technical malfunction" was defined in the absence of any surgical complication and inconsistent $\mathrm{PbtO}_{2}$ values with the absence of $\mathrm{PbtO}_{2}$ response to the increase of the fraction of inspired oxygen to $100 \%$ for 15 minutes (i.e. increase $<10 \mathrm{mmHg}$ ). 
Descriptive statistics were computed for all study variables. A Kolmogorov-Smirnov test was used and histograms and normal-quantile plots were examined to verify the normality of distribution of continuous variables. Discrete variables were expressed as counts (percentage) and continuous variables as means \pm SD or median [25th-75th percentiles]. Demographics and clinical differences between subgroups of patients (TBI vs non-TBI patients; iMMM with complications vs. no complication; iMMM placement in non-working hours vs. working hours; iMMM placement under antiaggregant/anticoagulant therapy vs. others; $\mathrm{PbtO}_{2}$ alone vs $\mathrm{PbtO}_{2}+\mathrm{iEEG} / \mathrm{MD}$ ) were assessed using a chi-square, Fisher's exact test, Student's ttest, or Mann-Whitney U test, as appropriate. A $p<0.05$ was considered as statistically significant. All descriptive statistics and statistical analyses were performed using " $\mathrm{R}$ " version 3.6.1.

\section{Results}

\section{Study population}

A total of 113 patients (median age 52 [41-62] years; 57/113, 50\% male gender) underwent 123 iMMM placements during the study period; of those, $93(76 \%)$ patients had only $\mathrm{PbtO}_{2}$ probe insertion and 30 (24\%) had also microdialysis and/or iEEG monitoring. ICP was monitored in all patients. SAH was the most frequent indication for iMMM $(n=56,50 \%) ; 35(31 \%)$ patients had TBI. Median GCS on admission was 7 [3-11]. Main characteristics of the study population are shown in Table 1.

\section{iMMM and complications}

Median duration of iMMM was 9 [3-14] days. Among the 10 patients that required a second iMMM (i.e. due to complications/malfunctioning in 8 and due to delayed new deterioration in 2), the placement occurred after 7 [3-9] days and numerically more frequent in SAH patients $(n=7)$ than others $(\mathrm{ICH}, \mathrm{n}=2$; $\mathrm{TBI}, \mathrm{n}=2$ ). At least one complication was observed in 67/123 (54\%) iMMM placement, corresponding to $58 / 113(51 \%)$ patients. No significant differences were observed between patients showing at least one iMMM-related complications when compared to others (Table 1).

Misplacement was observed in 16/123 (13\%) iMMM placements, consisting of 5 extra-axial (i.e. 4 subdural and 1 subarachnoid), 7 intra-axial (i.e. 6 paraventricular and one in deep grey matter) and 4 intraventricular probes. The 5 extra-axial probes and the single probe placed deeply in the grey matter were malfunctioning; all 6 paraventricular probes were functioning and gave consistent $\mathrm{PbtO}_{2}$ values. The 4 intraventricular probes were successfully repositioned (with reliable $\mathrm{PbtO}_{2}$ values) by unscrewing the bolt and at bedside without complications, resulting in a total of $6 / 16(38 \%)$ malfunctioning $\mathrm{PbtO}_{2}$ catheters in case of misplacement.

ICH was observed in 14 iMMM placements (11\%), including 7 tract hemorrhages (6\%, all Grade l; 3 of those $\mathrm{PbtO}_{2}$ catheters were also malfunctioning), 5 extra-dural hematomas (4\%, all Grade Il; of which one required surgical drainage - one $\mathrm{PbtO}_{2}$ catheters was malfunctioning) and 2 distal probe tip 
hematomas ( $2 \%$ - all Grade l; no $\mathrm{PbtO}_{2}$ catheter was malfunctioning). Only 2/14 (14\%) patients who experienced ICH were under antiaggregant/anticoagulant therapy (OR for increased risk of ICH 0.74 [0.153.58], $p=0.7$ vs. patients without antiaggregant/anticoagulant therapy).

Five placements were complicated by pneumocephalus ( $4 \%$ - one $\mathrm{PbtO}_{2}$ catheter was dysfunctional) and 4 with bone fragments ( $3 \%$ - one $\mathrm{PbtO}_{2}$ catheter was dysfunctional); none of these complications required additional surgery. No CNS infection related to iMMM was observed. Seven (6\%) probes were accidentally dislodged and, in 1 patient, the probe was replaced; 2 probes (2\%) were accidentally broken and no replacement was performed.

Ten $\mathrm{PbtO}_{2}$ probes (8\%) presented a technical malfunction (i.e. not attributable to surgical complications/adverse events) after a median of 9 [ranges: 2-24] days after initiation of monitoring and 4 of them were replaced. All complications are summarized in Table 2. Table 2 also shows a comparison between normally functioning probes $(n=101)$ and dysfunctional probes $(n=22)$. The association of several complications is depicted in Figure 2.

\section{iMMM and complications in subgroups}

The distribution of complications was similar in TBI and in non-TBI patients. Similarly, there were no differences in the rate of complications according to time of iMMM placement (non-working hours vs. working hours). There were no significant differences in the rate of complications between iMMM with only $\mathrm{PbtO}_{2}$ monitoring compared to iMMM including $\mathrm{PbtO}_{2}$, microdialysis and/or iEEG $(47 / 93,51 \%$ vs. $20 / 30,65 \%, p=0.22)$. These data are shown in table 3 .

\section{Discussion}

In this study, we observed that surgical complications and adverse events were common after iMMM placement, in particular probe misplacement and small-volume intracranial hemorrhage. No infection related to iMMM was observed. The type of acute brain injury and the timing of placement were not associated with a higher occurrence of iMMM-related complications. Only a minority of these complications were associated with iMMM dysfunction.

The most investigated surgical complications related to iMMM are probe misplacement and intracranial hemorrhage. Placement of $\mathrm{PbtO}_{2}$ probes outside the white matter, within a lesion or within a ventricle may yield irrelevant brain oxygen measurement and would result in additional costs (i.e. for probe replacement and/or because of lack of an adequate monitoring tool to guide interventions). Misplacement rates ranged from $0 \%$ to $14.3 \%$ across different studies $[2,8,10,17,18]$ and varied depending on the targeted area of the brain (i.e. higher when the target was a contusional then a healthy brain area). In our cohort, $13 \%$ of iMMM placement was associated with probe misplacement. Although this is quite higher than in most of previous reports, we investigated a heterogeneous cohort of patients with different forms of brain injury, while most of other studies focused on TBI patients. Future 
prospective studies evaluating with more accuracy the occurrence of iMMM-related complications should therefore include different forms of brain injury to better evaluate the potential role of the underlying disease in the occurrence of such complications.

Conversely, the occurrence of ICH was relatively low. In our series, where all patients underwent cerebral CT-scan after iMMM placement, tract and distal probe hemorrhages were evaluated by an independent radiologist who reviewed all postoperative imaging, including immediate post-placement but also delayed imaging studies. Moreover, only one case required surgical drainage (i.e. a compressive right parasagittal extradural hematoma). Dings et al. [8] described a similar occurrence of ICH due to placement of the $\mathrm{PbtO}_{2}$ probes close to the sagittal sinus, which should require a particular attention from physicians placing iMMM. Considering the variable occurrence of $\mathrm{ICH}$ due to iMMM placement reported in the literature, ranging from $0 \%$ to $40.5 \%[2,8,10,17,18]$, large multicentric registries are required to better describe the occurrence of such complication, its localization and size, the consequences on patients' clinical status as well as related interventions.

We observed no infection related to the iMMM placement. In fact, infections due to this type of intraparenchymal monitoring appear to be rare: in the largest series available including 501 patients, only one infection was reported [2]. On the other hand, accidental dislodgment and probe breaking are usually reported, ranging from $5.9 \%$ to $7.4 \%$ and from $2.5 \%$ to $4.5 \%$, respectively $[2,8,10,17,18]$. Whether these complications occur because of agitation or discomfort, during daily standard interventions (i.e. changes in bed positioning, physical therapy) or during transport (i.e. to perform brain imaging or other diagnostic/therapeutic procedures), it remains unclear from our retrospective data. Neuro-critical patients often require great manipulation and transportation which may make them vulnerable to these adverse events [10]. An interesting dynamic approach to adverse events was proposed by Foreman et al. [10], who quantified sudden stops of data recording as discontinuations, resulting either from dislodgement or unplugging by time tracking them as one-off events rather than only reporting their occurrence. During a median monitoring time of 97 hours, device discontinuation was noted in 25/43 (58\%) patients and concerned the combined ICP/PbtO 2 probe in $7(16 \%)$ cases, with a total of $4 \%$ of the recorded data considered as unusable. They also found a significant association between discontinuation and the number of patient trips for procedures or imaging.

Finally, despite complications and technical malfunctioning, iMMM appears to be safe, as only one additional surgery with no subsequent short-term neurological sequelae was observed. Moreover, both hospital mortality rate and neurological outcome were similar between patients that experienced at least one complication when compared to others. However, 10 (8\%) probes presenting a technical malfunction independently from other complications and, in some cases, this occurred within the first week of monitoring. The additional costs for probe replacement as well as the immediate loss of relevant monitoring data in these patients should also be further evaluated in larger cohorts, as it might be important information for centers who would decide to initiate placing iMMM in their routine practice. 
This study has some limitations due to its monocentric retrospective design, which limit the generalization of the main findings. Also, we did not specifically investigate long-term effects of the reported complications. Moreover, the role of neurosurgeons' skills was not considered into the analysis as iMMM placement was performed by rotating residents supervised by senior neurosurgeons with no main operator clearly identified into medical charts. Second, we used a triple lumen bolt device placed into the operating room and our findings do not apply to other possible solutions (i.e. double lumen bolts or subcutaneous tunelization without bolt) or setting (i.e. placement into the ICU and/or by a nonneurosurgeon). Third, the $\mathrm{PbtO}_{2}$ was the sole modality concerned by technical malfunction report, as being the only one used in clinical routine (i.e. microdialysis and iEEG data were only collected for research purposes).

\section{Conclusion}

iMMM placement including $\mathrm{PbtO}_{2}$ monitoring was associated with several mild complications but had an acceptable short-term safety profile in our institution. These data underline the need to standardize the reporting of technical and surgical iMMM complications to better evaluate its risk/benefit ratio. International collaboration through prospective multicentric data collection according to well-defined complications would promote the optimal use of iMMM.

\section{Declarations}

\section{Funding}

The research was not supported by any company. The devices were bought by the intensive care unit and the neurosurgery department to be used in a daily clinical practice.

\section{Conflicts of interest/Competing interests}

The authors declare that they have no conflict of interest.

Availability of data and material

All the data are available on demand to mejdi.albarajraji@gmail.com.

Code availability

Not applicable

Authors' contributions (optional: please review the submission guidelines from the journal whether statements are mandatory)

Not mandatory 
Additional declarations for articles in life science journals that report the results of studies involving humans and/or animals

Not applicable

\section{Ethics approval}

Ethical approval was obtained from ethics committees of the Erasme Hospital, Free University of Brussels, Brussels, Belgium: file EC P2020/019.

\section{Consent to participate}

For this type of study formal consent is not required.

Consent for publication

Consent to submit has been received from all co-authors and responsible authorities at the institute/organization where the work has been carried out before the work issubmitted.

\section{References}

1. Alali AS, Fowler RA, Mainprize TG, Scales DC, Kiss A, de Mestral C, Ray JG, Nathens AB (2013) Intracranial pressure monitoring in severe traumatic brain injury: results from the American College of Surgeons Trauma Quality Improvement Program. J Neurotrauma 30(20):1737-1746

2. Bailey RL, Quattrone F, Curtin C, Frangos S, Maloney-Wilensky E, Levine JM, LeRoux PD (2019) The Safety of Multimodality Monitoring Using a Triple-Lumen Bolt in Severe Acute Brain Injury. World Neurosurg 130:e62-e67

3. Carney N, Totten AM, O'Reilly C et al (2017) Guidelines for the Management of Severe Traumatic Brain Injury, Fourth Edition. Neurosurgery 80(1):6-15

4. Chesnut RM, Temkin N, Carney N et al (2012) A Trial of Intracranial-Pressure Monitoring in Traumatic Brain Injury. N Engl J Med 367(26):2471-2481

5. Chin JH, Vora N (2014) The global burden of neurologic diseases. Neurology 83(4):349-351

6. Citerio G, Oddo M, Taccone FS (2015) Recommendations for the use of multimodal monitoring in the neurointensive care unit. Curr Opin Crit Care 21(2):113-119

7. Dewan MC, Rattani A, Gupta S et al (2018) Estimating the global incidence of traumatic brain injury. J Neurosurg 1-18

8. Dings J, Meixensberger J, Jäger A, Roosen K (1998) Clinical experience with 118 brain tissue oxygen partial pressure catheter probes. Neurosurgery 43(5):1082-1095

9. Farahvar A, Gerber LM, Chiu Y-L, Carney N, Härtl R, Ghajar J (2012) Increased mortality in patients with severe traumatic brain injury treated without intracranial pressure monitoring. J Neurosurg 
117(4):729-734

10. Foreman B, Ngwenya LB, Stoddard E, Hinzman JM, Andaluz N, Hartings JA (2018) Safety and Reliability of Bedside, Single Burr Hole Technique for Intracranial Multimodality Monitoring in Severe Traumatic Brain Injury. Neurocrit Care 29(3):469-480

11. Hawryluk GWJ, Aguilera S, Buki A et al (2019) A management algorithm for patients with intracranial pressure monitoring: the Seattle International Severe Traumatic Brain Injury Consensus Conference (SIBICC). Intensive Care Med 45(12):1783-1794

12. Horan TC, Andrus M, Dudeck MA (2008) CDC/NHSN surveillance definition of health care-associated infection and criteria for specific types of infections in the acute care setting. Am J Infect Control 36(5):309-332

13. Knaus WA, Draper EA, Wagner DP, Zimmerman JE (1985) APACHE II: a severity of disease classification system. Crit Care Med 13(10):818-829

14. Le Roux P, Menon DK, Citerio G et al (2014) Consensus summary statement of the International Multidisciplinary Consensus Conference on Multimodality Monitoring in Neurocritical Care: a statement for healthcare professionals from the Neurocritical Care Society and the European Society of Intensive Care Medicine. Intensive Care Med 40(9):1189-1209

15. Roh D, Park S (2016) Brain Multimodality Monitoring: Updated Perspectives. Curr Neurol Neurosci Rep 16(6):56

16. Samaniego EA, Hasan DM (2019) In Reply: External Ventricular Drain and Hemorrhage in Aneurysmal Subarachnoid Hemorrhage Patients on Dual Antiplatelet Therapy: A Retrospective Cohort Study. Neurosurgery 84(1):E99-E100

17. van Santbrink H, Maas Al, Avezaat CJ (1996) Continuous monitoring of partial pressure of brain tissue oxygen in patients with severe head injury. Neurosurgery 38(1):21-31

18. Stuart RM, Schmidt M, Kurtz $P$ et al (2010) Intracranial multimodal monitoring for acute brain injury: a single institution review of current practices. Neurocrit Care 12(2):188-198

19. Teasdale G, Maas A, Lecky F, Manley G, Stocchetti N, Murray G (2014) The Glasgow Coma Scale at 40 years: standing the test of time. Lancet Neurol 13(8):844-854

20. Vincent JL, Moreno R, Takala J, Willatts S, De Mendonça A, Bruining H, Reinhart CK, Suter PM, Thijs LG (1996) The SOFA (Sepsis-related Organ Failure Assessment) score to describe organ dysfunction/failure. On behalf of the Working Group on Sepsis-Related Problems of the European Society of Intensive Care Medicine. Intensive Care Med 22(7):707-710

\section{Tables}

Table 1. Characteristics of the study population, according to the occurrence of invasive multimodal monitoring (iMMM) complications. 


\begin{tabular}{|c|c|c|c|c|}
\hline & $\begin{array}{c}\text { ALL } \\
(n=113)\end{array}$ & $\begin{array}{l}\text { Without Complications } \\
\qquad(n=55)\end{array}$ & $\begin{array}{l}\text { With Complications } \\
\qquad(n=58)\end{array}$ & $P$ value \\
\hline \multicolumn{5}{|l|}{ graphics } \\
\hline yender, n (\%) & $57(50)$ & $28(51)$ & $29(50)$ & 0.99 \\
\hline edian (IQR) & 52 [41-62] & $52[42-60]$ & $53[41-65]$ & 0.56 \\
\hline \multicolumn{5}{|l|}{ rbidities } \\
\hline al Hypertension, n (\%) & $28(25)$ & $13(24)$ & $15(26)$ & 0.83 \\
\hline tes, n (\%) & $7(6)$ & $6(11)$ & $4(7)$ & 0.52 \\
\hline ic Heart Disease, $\mathrm{n}(\%)$ & $9(8)$ & $7(13)$ & $6(10)$ & 0.77 \\
\hline us Neurological Disease, n (\%) & $2(2)$ & $2(4)$ & $3(5)$ & 0.99 \\
\hline $\mathrm{n}(\%)$ & $7(6)$ & $5(9)$ & $3(5)$ & 0.48 \\
\hline irrhosis, n (\%) & $1(1)$ & 0 & $2(3)$ & 0.50 \\
\hline $\mathrm{r}, \mathrm{n}(\%)$ & $4(4)$ & $4(7)$ & $2(3)$ & 0.43 \\
\hline ic Renal Disease, n (\%) & $2(2)$ & $1(2)$ & $1(2)$ & 0.99 \\
\hline \multicolumn{5}{|l|}{ dmission } \\
\hline HE II score, median (IQR) & 19 [14-22] & 20 [15-23] & 18 [14-21] & 0.38 \\
\hline score, median (IQR) & $9[6-11]$ & $9[5-10]$ & $9[7-11]$ & 0.32 \\
\hline sion GCS, median (IQR) & $7[3-11]$ & $6[3-10]$ & $8[4-12]$ & 0.12 \\
\hline lying Disease & & & & 0.28 \\
\hline$(\%)$ & $35(31)$ & $17(31)$ & $18(31)$ & \\
\hline.$(\%)$ & $56(50)$ & $29(53)$ & $27(47)$ & \\
\hline ( & $20(18)$ & $7(13)$ & $13(22)$ & \\
\hline al, n (\%) & $2(2)$ & $2(4)$ & - & \\
\hline \multicolumn{5}{|l|}{ J ICU stay } \\
\hline ressors, n (\%) & $110(97)$ & $55(100)$ & $55(95)$ & 0.24 \\
\hline pic agents, $\mathrm{n}(\%)$ & $36(32)$ & $15(27)$ & $21(36)$ & 0.32 \\
\hline inical ventilation, $\mathrm{n}(\%)$ & $113(100)$ & $55(100)$ & $58(100)$ & 0.99 \\
\hline replacement therapy, n (\%) & $3(3)$ & 0 & $3(5)$ & 0.99 \\
\hline \multicolumn{5}{|l|}{ mes } \\
\hline ngth of stay, days & $15[9-23]$ & $13[7-20]$ & 18 [11-30] & 0.03 \\
\hline tal Mortality, n (\%) & $54(48)$ & $30(55)$ & $24(41)$ & 0.19 \\
\hline orable neurological outcome, n (\%) & $73(65)$ & $42(76)$ & $30(53)$ & 0.02 \\
\hline
\end{tabular}

COPD: chronic obstructive pulmonary disease; ICU: intensive care unit; TBI: traumatic brain injury; ICH: intracranial hemorrhage; SAH: subarachnoid hemorrhage; SOFA: sequential organ failure assessment; APACHE : acute physiology and chronic health evaluation; IQR: interquartile range.

Table 2 : Complications, adverse and probe dysfunction events related to the placement of invasive multimodal neuromonitoring $(n=123)$. 
All probes

Normally functioning

Mal functioning

p-

$(\mathrm{N}=123)$

probes $(\mathrm{N}=111)$

probes $(\mathrm{N}=22)$

value

complications

\begin{tabular}{lcccc}
\hline ment, n (\%) & $16(13)$ & $10(10)$ & $6(27)$ & 0.03 \\
\hline $\begin{array}{l}\text { lial Bone } \\
\text { s }\end{array}$ & $4(3)$ & $3(3)$ & $1(5)$ & 0.71 \\
\hline ephalus & $5(4)$ & $4(4)$ & $1(5)$ & 0.90 \\
\hline ction, n (\%) & 0 & 0 & 0 & - \\
\hline ial hemorrhage, & $14(11)$ & $10(10)$ & $4(18)$ & 0.27 \\
\hline mplications & & & \\
\hline l malfunction, $\mathrm{n}$ & $10(8)$ & 0 & $10(45)$ & - \\
\hline
\end{tabular}

Adverse events

æl dislodgement,

7 (6)

of any probe or

se, $\mathrm{n}(\%)$

$2(2)$

nent required, $\mathrm{n}$

$9(7)$

CNS: central nervous system

Table 3: Occurrence of complications according to some patients' characteristics at the moment of invasive multimodal monitoring (iMMM) placement. 


\begin{tabular}{|c|c|c|c|c|c|c|c|c|c|c|c|c|}
\hline & $\begin{array}{c}\text { Non- } \\
\text { TBI } \\
(\mathrm{N}=86)\end{array}$ & $\begin{array}{c}\mathrm{TBI} \\
(\mathrm{N}=37)\end{array}$ & $\begin{array}{c}\mathrm{P} \\
\text { value }\end{array}$ & $\begin{array}{c}\text { Non- } \\
\text { working } \\
\text { hours } \\
(\mathrm{N}=46)\end{array}$ & $\begin{array}{c}\text { Working } \\
\text { hours } \\
(\mathrm{N}=77)\end{array}$ & $\begin{array}{c}\mathrm{P} \\
\text { value }\end{array}$ & $\begin{array}{c}\text { No } \\
\text { AP/AC } \\
(\mathrm{N}=102)\end{array}$ & $\begin{array}{l}\mathrm{AP} / \mathrm{AC} \\
(\mathrm{N}=22)\end{array}$ & $\begin{array}{c}\mathrm{P} \\
\text { value }\end{array}$ & $\begin{array}{c}\mathrm{PbtO}_{2} \\
\text { alone } \\
(\mathrm{n}=92)\end{array}$ & $\begin{array}{l}\text { Combined } \\
\quad(n=31)\end{array}$ & $\begin{array}{c}\mathrm{P} \\
\text { value }\end{array}$ \\
\hline $\begin{array}{l}\text { ine } \\
\text { on, } n\end{array}$ & 47 (55) & $20(54)$ & 0.99 & 45 (58) & $22(48)$ & 0.27 & $55(55)$ & $12(55)$ & 0.99 & $\begin{array}{c}47 \\
(51)\end{array}$ & 20 (65) & 0.22 \\
\hline ənt, $n$ & 13 (15) & $3(8)$ & 0.39 & 10 (13) & $6(13)$ & 0.99 & 15 (15) & $1(5)$ & 0.30 & $\begin{array}{c}14 \\
(15) \\
\end{array}$ & $2(7)$ & 0.35 \\
\hline lents, & $3(4)$ & $1(3)$ & 0.99 & $3(4)$ & $1(2)$ & 0.99 & $4(4)$ & 0 & 0.99 & $2(2)$ & $2(7)$ & 0.26 \\
\hline halus, & $4(5)$ & $1(3)$ & 0.99 & $4(5)$ & $1(2)$ & 0.65 & $5(5)$ & $1(2)$ & 0.58 & $2(2)$ & $3(10)$ & 0.10 \\
\hline \%) & $9(11)$ & $5(14)$ & 0.76 & $9(12)$ & $5(11)$ & 0.98 & $12(12)$ & $2(9)$ & 0.99 & $\begin{array}{r}12 \\
(13) \\
\end{array}$ & $2(7)$ & 0.51 \\
\hline 3nt, n & $4(5)$ & $3(8)$ & 0.44 & $6(8)$ & $1(2)$ & 0.26 & $5(5)$ & $2(10)$ & 0.35 & $4(4)$ & $3(10)$ & 0.37 \\
\hline $1(\%)$ & $2(2)$ & 0 & 0.99 & 0 & $2(4)$ & 0.14 & 1(1) & $1(5)$ & 0.32 & $1(1)$ & $1(3)$ & 0.45 \\
\hline $\begin{array}{l}\text { lent } \\
\text { I(\%) }\end{array}$ & $7(8)$ & $2(5)$ & 0.72 & $5(7)$ & $4(9)$ & 0.72 & $4(4)$ & $5(23)$ & 0.009 & $6(7)$ & $3(10)$ & 0.69 \\
\hline $\begin{array}{l}\mathrm{al} \\
\mathrm{in}, \mathrm{n}\end{array}$ & $7(8)$ & $3(8)$ & 0.99 & $5(7)$ & $5(11)$ & 0.50 & $5(7)$ & 5 (11) & 0.50 & $6(7)$ & $4(13)$ & 0.27 \\
\hline
\end{tabular}

CNS: central nervous system; TBI: traumatic brain injury; $\mathrm{AP}=$ anti-platelet; $\mathrm{AC}=$ anticoagulant

Figures 


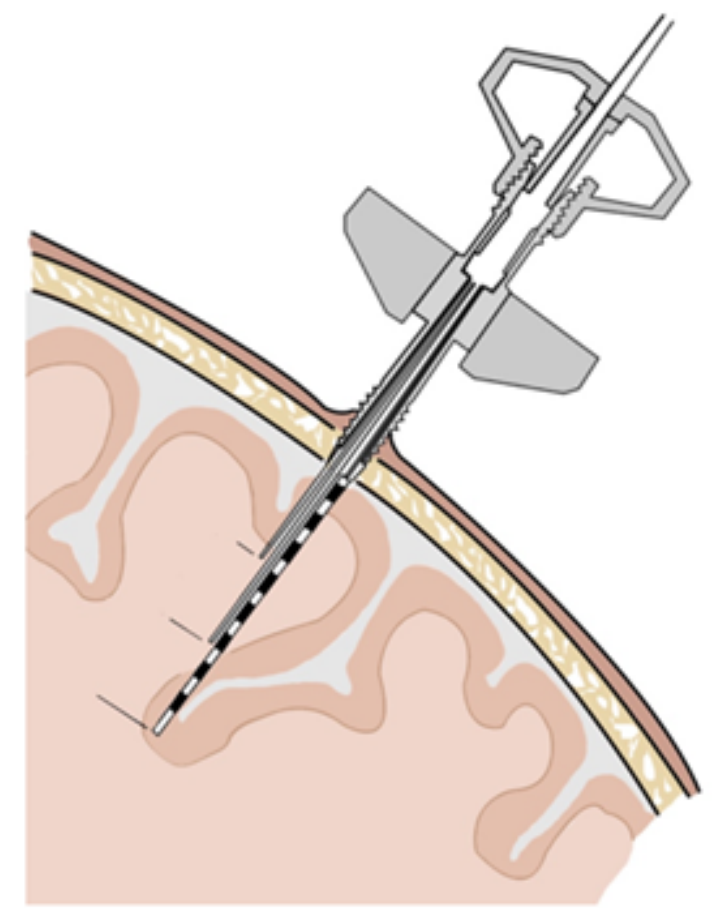

Creation: original content, using commercially available photo editing software: Adobe Photoshop CS 6

\section{Figure 1}

Schematic illustration of the triple lumen iMMM bolt placement with its three probes ( $\mathrm{PbtO} 2$, microdialysis and EEG).

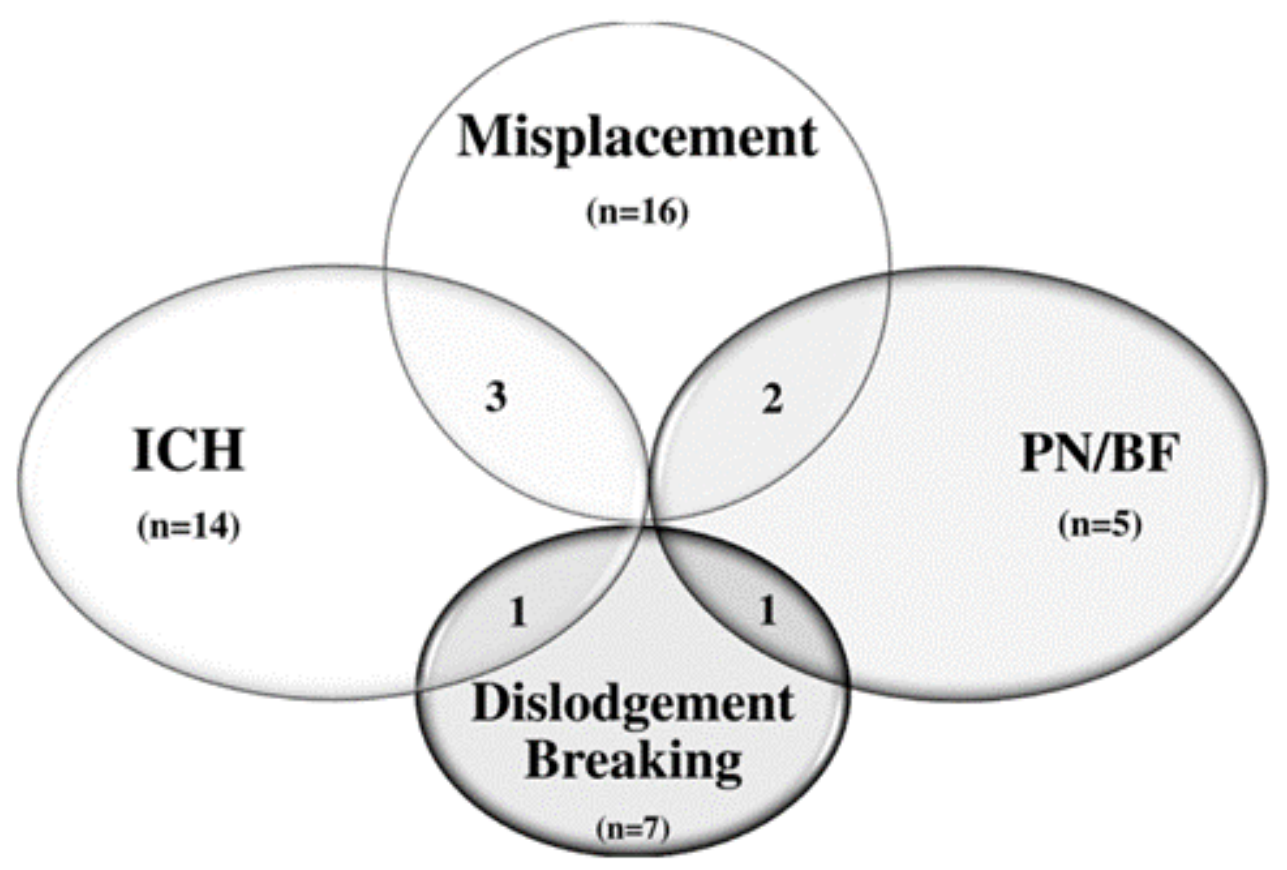

Creation: original content, using commercially available text editing software: Microsoft Word

Figure 2 
Association of multiple surgical complications and adverse events. ICH: intracranial hemorrhage; PN: pneumocephalus; BF: bone fragment. 